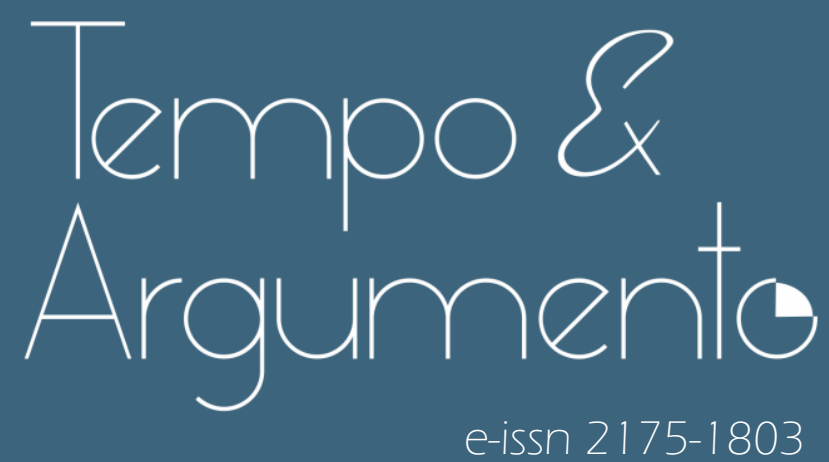

\title{
Rupturas conceituais de segurança e meio ambiente no Antropoceno: os nexos securitários em formação desde o pós-guerra fria
}

- Hermes de Andrade Júnior

Doutor em Saúde Pública pela Fundação Oswaldo Cruz (Fiocruz). Doutorando em Inovação Social, Criatividade e Sustentabilidade na Universidade de Vigo Espanha. Investigador do Centro de Investigação e Desenvolvimento do Instituto Universitário Militar (CIDIUM) - Portugal).

Lisboa - PORTUGAL lattes.cnpq.br/ 1621515575285249

handradejunior@gmail.com

(D) orcid.org/0000-0002-3667-1354

- Ana Paula Brandão

Doutora em Ciência Política e Relações Internacionais pela Universidade do Minho - Portugal. Professora e membro integrado do Centro de Investigação em Ciência Política (CICP), da Escola de Economia e Gestão da Universidade do Minho.

Braga - PORTUGAL

uminho.pt/investigadores/ana-paula-brandao/

abrandao@eeg.uminho.pt

(D) orcid.org/0000-0002-4439-3112

Para citar este artigo:

ANDRADE JÚNIOR, Hermes; BRANDÃO, Ana Paula. Rupturas conceituais de segurança e meio ambiente no antropoceno: os nexos securitários em

formação desde o pós-guerra fria. Tempo e Argumento, Florianópolis, v. 13, n. 32, e0 109, jan./abr. 2021.

doi http://dx.doi.org/10.5965/2175180313322021e0109

Recebido: 29/10/2020

Aprovado: $11 / 03 / 2021$ 


\title{
Rupturas conceituais de segurança e meio ambiente no Antropoceno: os nexos securitários em formação desde o pós-guerra fria ${ }^{1}$
}

\begin{abstract}
Resumo
O modelo do Antropoceno refere-se às perturbações na superfície terrestre causadas pela intensa atividade humana. Estando associado a um novo intervalo na história geológica da Terra, ele tem sido abordado por diversas áreas de conhecimento das chamadas ciencias da Terra, chegando agora até às ciencias sociais e humanidades, desde a sua implantação. As Relações Internacionais (RI) procuram uma melhor especificidade de suas funções diante do Antropoceno, alargando seu campo de atuação. No campo da Segurança, afirma-se que os atores estejam mais conectados e comprometidos entre si e que o significado de Segurança baseado no ator estatal e nos setores político e militar não faz mais sentido no modelo antropocênico e que a transdisciplinaridade (para a disciplina de relações internacionais e além dela) deva ser afirmada. Colaborando com um manifesto lançado em conferencia patrocinada pela Revista Millenium, da London School of Economics trazemos o corte temporal do pós-Guerra Fria para alargar o debate sócio-ambiental em termos transdisciplinares ao campo dos estudos de segurança. O Antropoceno prenuncia uma época de insegurança. Embora a atenção à segurança como ameaça tenha crescido nas últimas duas décadas em um franco estímulo ao debate do pós-Guerra Fria e a securitização seja visível no sistema global, persiste um grande número de nexos de segurança em construção transdisciplinar que merecem reexame crítico diante do fenômeno da degradação ambiental criada dentro do Antropoceno conceitual, que preconiza uma ameaça bipolar humanonatureza.
\end{abstract}

Palavras-chave: Segurança ambiental. Segurança ecológica. Antropoceno. Crise ambiental. Estudos de Segurança. Transdisciplinaridade. Pós-Guerra Fria.

\section{Conceptual breaches of security and environment in the Anthropocene: the security nexuses in formation since the post cold war}

\begin{abstract}
The Anthropocene model refers to disturbances on the earth's surface caused by intense human activity. Being associated with a new interval in the geological history of the Earth, it has been approached by several areas of knowledge of the so-called Earth sciences, reaching now to the social sciences and humanities, since its implantation. International Relations (IR) seek a better specificity of their functions vis-à-vis the Anthropocene, expanding their field of action. In the field of Security, it is stated that the actors are more connected and committed to each other and that the meaning of Security based on the state actor and in the political and military sectors no longer makes sense in the anthropocentric model and that transdisciplinarity (for the discipline of international relations and beyond) must be affirmed. Collaborating with a manifesto launched at a conference sponsored by the Millennium Journal, of the London School of Economics, we bring the post-Cold War time cut to broaden the socio-environmental debate in transdisciplinary terms to the field of security studies. The Anthropocene foreshadows a time of insecurity. Although attention to security as a threat has grown in the past two decades in a frank stimulus to the post-Cold War debate and securitization is visible in the global system, a large number of security nexuses in transdisciplinary construction persist that deserve critical review in the face of phenomenon of environmental degradation created within the conceptual Anthropocene, which advocates a bipolar human-nature threat.
\end{abstract}

Keywords: Environmental security. Ecological security. Anthropocene. Environmental crisis. Security studies. Transdisciplinarity. Post-cold war.

\footnotetext{
Este estudo foi realizado no Centro de Investigação em Ciência Política (UIDB/00758/2020), Universidade do Minho, com o apoio da Fundação para a Ciência e Tecnologia (FCT) através de fundos nacionais.

This study was conducted at the Research Center in Political Science (UIDB /00758/2020), University of Minho, and supported by the Portuguese Foundation for Science and Technology (FCT) and the Portuguese Ministry of Education and Science through national funds.
} 


\section{Introdução}

A crise ambiental abriga uma complexidade de fenômenos que desafiam constantemente as mais variadas mentes e organizações, fundindo vertentes de estudos sobre a crise humana do tempo presente. Diante do risco ecológico, há o pressuposto de novas ameaças em um cenário de hostilidades latentes que já foram materializadas por guerras de imensas proporções no Século XX. O risco ecológico coloca o mundo em um estado de alerta extremo, com ressignificação e reorientação do curso da história. São impostos limites ao crescimento econômico e populacional, aos desequilíbrios ecológicos, às capacidades de sustentação da vida, à pobreza e desigualdade social (LEFF, 2000) e ao armamentismo, ressaltando que as atividades militares são, por si só, degradantes (RENNER, 1991).

Diante da discussão sobre limites a serem impostos às atividades produtivas humanas, a questão de estarmos ou não em uma nova era (época) geológica denominada de Antropoceno tem sido discutida de maneira bastante intensa em vários setores da comunidade científica. Debates envolvem o papel da Humanidade como agente geológico, assim como as maneiras pelas quais os sistemas produtivos apropriam-se dos recursos planetários e também sobre as suas responsabilidades no processo. Na abordagem antropocênica, as atividades humanas como um todo (predominantemente o sistema econômico global) são agora protagonistas da mudança no Sistema Terrestre - a soma dos processos físicos, químicos, biológicos e humanos em interação com o planeta (STEFFEN; BROADGATE; DEUTSCH, 2015).

O marco que impulsionou o conceito do Antropoceno, o trabalho de Crutzen e Stoermer (2000), apresentou circunstâncias da situação crítica em termos planetários. Os autores do artigo eram o então ganhador do Prêmio Nobel de Química Paul Crutzen e Eugene Stoermer. Dois anos depois, Crutzen publicou o artigo Geology of Mankind na Revista Nature (CRUTZEN, 2002), argumentando que as últimas décadas do século 18 deveriam ser o início do Antropoceno. 0 conceito de Antropoceno e sua modelagem empírica estão sob avaliação da "Academy of Geosciences", consubstanciada na International Commission for 
Stratigraphy (ICS), o maior e mais antigo corpo científico da International Union of Geological Sciences (IUGS). O principal objetivo do IUGS é definir precisamente as unidades globais (sistemas, séries e estágios) da Carta Cronoestratigráfica Internacional, estabelecendo padrões globais para a escala da história da Terra. Para alguns autores, o Antropoceno já é estratigráfico (WATERS et al., 2016; ZALASIEWICZ et al., 2016), mas haverá uma decisão final para reconhecer o modelo do Antropoceno como geologicamente válido durante o Congresso Internacional de Geologia em Nova Delhi, Índia², que foi adiado para este ano de 2021, devido à pandemia SARS Cov 2.

Tendo enquadrado conceitualmente a participação antrópica na crise ambiental, o modelo conceitual e de datação do Antropoceno busca explicações, significados e soluções a partir de várias disciplinas científicas em transdisciplinarização (ANDRADE JÚNIOR, 2020). A manifestação da transdisciplinaridade (NICOLESCU, 2000) para o Antropoceno havia sido sugerida por Oldfield et al. (2013), evocando um consórcio de disciplinas a estudá-lo dada a complexidade dos fatos, dados, agravos e análises sócio ambientais envolvidas.

Entretanto, tem havido uma resistência por parte das Ciências Sociais e Humanidades que o consideram sobremodo generalista e pouco afeto ao papel destas ciências. A crítica forte repousa sobre a própria ontologia do modelo antropocênico. Os historiadores Bonneuil e Fressoz (2016) promoveram uma desconstrução da "narrativa geocrática do Antropoceno", criticando a afirmação desse status quo apresentando narrativas históricas ainda pouco consideradas e discutidas que abrangem diferentes dimensões do estudo "antropocênico" em um contexto global e um nível planetário (Ver BONNEUIL; FRESSOZ, 2016). IsSO se justifica, por exemplo, pelos argumentos de que o industrialismo, colonialismo, guerras, tecnologias ameaçadoras, genocídios, escravidão, energia nuclear e capitalismo são articulados de forma diferente (mas muitas vezes relacionados) às desigualdades das condições sócio ambientais que levam ao "forçamento planetário" (BELCHER; SCHMIDT, 2021).

2 Para ver detalhes deste evento: https://www.36igc.org/ 
As Relações Internacionais (RI) procuram uma melhor especificidade de suas funções diante do conceito do Antropoceno, alargando seu campo de atuação. Chamando de "Planet Politics", Burke et al. (2016) procuraram fomentar um diálogo sobre os limites de RI e de suas possibilidades em formar alianças, promovendo discussões com outras ciências, diplomatas e líderes em conjunto (das geociências, do direito ambiental progressivo, dos estudos de segurança) para responder às "mudanças forjadas pelo Antropoceno".

No campo da Segurança, afirmaram que os atores estejam mais conectados e comprometidos entre si; que a "Era dos Estados baseada na bola de bilhar", que a Segurança Nacional baseada no ator estatal e nos setores político e militar não faz mais sentido no modelo antropocênico e que a transdisciplinaridade (da disciplina de relações internacionais e além dela) deva ser afirmada (BURKE et al., 2016).

Colaborando com o esforço de Burke et al. (2016), o objetivo deste ensaio é alargar a discussão sobre os Estudos de Segurança do pós-Guerra Fria, examinando a sua intensificação de forma crítica, observando a evolução dos conceitos de segurança desde a Guerra Fria, acompanhando a transdisciplinarização, a tendência de securitização e estudando alguns cenários correlatos do contexto latino-americano.

O estudo está estruturado no que chamamos de rupturas $^{3}$ conceituais de segurança em cinco seções: (1) debate sobre a segurança (compreendido no campo das Relações Internacionais) desde o pós-guerra fria; (2) aproximações e distanciamentos conceituais sobre segurança; (3) transdisciplinarização através dos nexos securitários; (4) nexo transdisciplinar de segurança e meio ambiente e (5) discussão preliminar focando o contexto das relações internacionais da América do Sul e do Brasil e em alguns aspectos da Amazônia.

\footnotetext{
${ }^{3}$ Consideradas como modificações significativas do status quo que levam às ponderações sobre o Antropoceno nas Relações Internacionais.
} 
Ruptura Conceitual 1: O Pós-Guerra Fria e o Debate sobre a Segurança ${ }^{4}$ Aproximadamente até o início da década de 70, ou seja, durante os primeiros vinte e cinco anos da Guerra Fria, o Estado monopolizara os papéis de sujeito e objeto da Segurança. No sistema internacional, como resultado desse monopólio, as questões de segurança foram expressas por meio de relações interestatais em que a condição do Estado em termos de segurança estava associada, quase que exclusivamente, ao poder militar.

Imediatamente após a Guerra Fria, o vazio deixado pelo término da ameaça soviética intensificou a reflexão sobre a segurança como conceito, como disciplina e como política, multiplicando-se as vozes em defesa de uma nova forma de pensar as relações internacionais como superadora do Sistema de Estados Westfaliano ${ }^{5}$, um considerável paradigma adotado pela Guerra Fria.

A Paz de Westfália pode ser considerada como marco gerador do espaço de negociação política entre potências com certo grau de autonomia na Europa, criando o conceito de Estado Nacional. Sem ignorar ou deixar de investigar as inter-relações entre os centros de poderes independentes como tribos, clãs, hordas, cidades-estado, principados, etc. em práticas variadas de coordenação ou subordinação, historiadores e teóricos do campo de estudo das Relações Internacionais compartilham a ideia de que um espaço físico e sócio-jurídico pode ser chamado de internacional se houver a definição de um espaço físico e sócio-jurídico interno ou doméstico (LUZURIAGA; GONZÁLEZ, 2018).

Com a globalização, as fronteiras territoriais tornaram-se permeáveis às novas ameaças e o antigo conceito de segurança, fortemente baseado na defesa territorial e nas respectivas fronteiras, deixou de ser eficaz. O caráter global e transnacional das novas ameaças deu origem a um ambiente estratégico mais complexo. Sempre se tratou a segurança como a busca da libertação relativamente à ameaça (GARCIA, 2006). Este embrião conceitual de segurança

\footnotetext{
${ }^{4}$ Versão adaptada de BRANDÃO, 2011.

5 A Paz de Westfália encerrou a Guerra dos Trinta Anos (1648). Através dela, a soberania recebeu reconhecimento internacional e foi limitada no seu exercício nos séculos subsequentes. Estados negociadores na intenção de representar o "soberano" mantém seu valor absoluto e total dentro das fronteiras, mas externamente estão limitados por outras soberanias e por normas do Direito Internacional (Ver LUZURIAGA; GONZÁLEZ, 2018).
} 
evoluiu, alargando-se a outras dimensões, tornando-se mais abrangente ao ponto de análise sofisticada do tipo, origem, objeto e provedor da ameaça.

Tende-se ainda a superar a ética maquiavélica e a filosofia da guerra Clausewitziana ${ }^{6}$ :

No mundo do pós-Guerra Fria, as fronteiras desenhadas entre Estados, entre Estados e sociedade civil, e entre áreas funcionais tais como política, economia e cultura estão desabando... [...] concessões de segurança vigentes centradas no Estado e orientadas para o exterior são inadequadas para capturar a complexidade das novas e multifacetadas relações internacionais. (VAYRYNEN, 1995, p. 259)

Finda a Guerra Fria, clamou-se pela defesa do alargamento e/ou do aprofundamento da segurança, bem como pela análise dos mecanismos do discurso securitário, desdobrando as perguntas: o que é a segurança? segurança de quem? (exemplificado por HAMMERSTAD, 2000) segurança de quê? segurança com que meios? quem securitiza? como securitiza? O debate sobre a natureza da ameaça e sobre os meios mais adequados para lutar contra ameaças complexas, conduziu ao questionamento sobre o objeto e o ator da segurança (MARTINELLI, 2016).

Uma dimensão multinível da segurança tornou-se evidente pelos proponentes da segurança da humanidade (segurança global), da segurança dos grupos (segurança societal) e da segurança individual (segurança humana). O alargamento traduziu-se na assunção da multissetorialidade da segurança sistematizada por Barry Buzan em States, People and Fear. segurança política, segurança militar, segurança econômica, segurança ambiental, segurança societal (BUZAN, 1991; BUZAN; WAEVER; WILDE, 1998; COLLINS, 2016; WAEVER et al., 1993), em um contexto em que "a crescente interdependência do mundo nos transportes, nas comunicações, no processamento de dados e nas tecnologias criou novas oportunidades para a humanidade, mas também tornou o mundo mais complexo e vulnerável" (FISCHER, 1993, p.167).

\footnotetext{
${ }^{6}$ A Guerra dos Trinta Anos conclui que a guerra é a fase mais elevada de utilização do instrumento militar pelos Estados. O estudo desse fenômeno e suas implicações no campo histórico e sociológico reconhece um lugar preponderante para Karl von Clausewitz, autor do famoso "On War" (Vom Kriege), publicado em 1832 após sua morte.
} 
Posteriormente à Guerra Fria, a segurança internacional alternativa à proposta da Guerra Fria parece atender ao surgimento de um tipo ideal de segurança global multidimensional que é "global, porque a interdependência e transnacionalização dos novos fenômenos de segurança permite ao conceito abranger significados não apenas localizados, mas planetários" (VILLA, 1999, p.99). É multidimensional, porque não se constitui só de conteúdo estratégicomilitar, mas também de outros conteúdos transnacionais, como explosão demográfica, desequilibrios ecológicos e migrações internacionais (VILLA, 1999), que fazem com que a segurança internacional seja encarada sob diferentes ângulos no Antropoceno. Porém, o mais relevante do ponto de vista conceitual é que o surgimento de uma noção de segurança global multidimensional acaba atingindo a unidade de análise fundamental do realismo: o Estado.

Cada vez mais, indivíduos e comunidades enfrentam ameaças sem inimigos, onde muitos desses agentes, forças e ideias políticas habituais nos dois últimos séculos não podem mais garantir a segurança (PRINS, 1994). Uma linha de abordagem mais crítica chega a questionar a viabilidade do Estado como comunidade política (LIPSCHULTZ, 1995; BOOTH, 2005), sustentando que, para reformulação positiva do termo ("segurança"), não basta superar a sua formulação negativa nem pugnar pela sua extensão, mas refletir sobre o que poderia significar uma segurança sem Estados (DALBY, 1991).

É o caso dos novos conceitos emergentes da dimensão multinivel. De acordo com Barry Buzan (1991)7, Segurança Social refere-se às ameaças à identidade da sociedade (idioma, religião, costumes, etc.) que podem colocar em risco sua sobrevivência como tal, entendendo a sociedade em seu sentido amplo como entidades relevantes étnicas ou de valor religioso.

A manifestação mais ampla da reconceitualização é constituída pelo conceito de Segurança Humana, cujo aparecimento formal está registrado nas edições do Relatório de Desenvolvimento Humano (IDH) do Programa das Nações Unidas para o Desenvolvimento (PNUD) (MAOS, 1996; MAOS; RUSSETT, 1993). O seu surgimento não deixa de estar relacionado com a falha que significa, no plano 
internacional, à utilização do conceito de segurança apenas em relação aos Estados. Essa opção evita as demandas de segurança dos indivíduos, que costumam estar mais associadas às questões do dia-a-dia do que a conflitos de natureza interestatais. A partir deste ponto de vista, a chave da Segurança Humana estaria na mutação do seu objeto de análise, que é transferido dos Estados para os indivíduos.

Uma nova derivação da dimensão multinível: a necessidade de detectar precocemente qualquer deterioração em ambientes de Segurança Humana confere a este conceito um forte conteúdo preventivo, que se articula através do acompanhamento de "indicadores de alerta precoce", especialmente concebidos para o efeito de natureza socioeconômica e política. Junto aos indicadores, novos conceitos derivados surgiram como os de: Segurança Alimentar, para monitoramento da oferta diária de calorías, do Índice de produção alimentar per capita e do grau de dependência da importação de alimentos; Segurança Econômica, relacionando as altas taxas de desemprego, diminuição da renda nacional real, altas taxas de inflação, grandes disparidades nos níveis de renda, desigualdades medidas no Índice de Desenvolvimento Humano; Segurança Política, para os casos de violações dos direitos humanos (inclui repressão política, tortura, desaparecimentos ou censura na mídia escrita, etc.) e dos gastos militares, medidos pela relação entre os gastos como atividades militares e os gastos totais com educação e saúde e Segurança Comunitária, onde os conflitos étnicos ou religiosos são medidos pela porcentagem da população que participa de tais conflitos e pelo número de vítimas (VILLANUEVA, 2000).

Segundo Tanno (2003) e estamos de acordo com isso, a análise das dinâmicas próprias de cada setor derivado de segurança pode ser interpretada como uma proposta teórica para a área de relações internacionais em geral e não apenas para os estudos de segurança. Tal hipótese é confirmada no artigo "Peace, Power and Security: Contending Concepts in the Study of International Relations", publicado por Buzan (1984). Nele, Buzan argumenta que entre os três conceitos-chave na disciplina de relações internacionais que são paz, segurança e poder, o conceito de segurança é aquele que confere maiores ganhos analíticos às análises de relações internacionais. Para ele, os conceitos de poder e paz, 
utilizados pelas perspectivas realista e idealista, respectivamente, não são adequados porque se remetem a visões extremadas do sistema internacional. É inexistente tanto a situação de paz total quanto a de tensão generalizada.

\section{Ruptura Conceitual 2: Aproximações e distanciamentos conceituais da Segurança}

A centralidade do conceito de segurança é o que distingue os Estudos de Segurança (ES) das disciplinas que os precederam (Estudos da Guerra, Estudos Estratégicos, História Militar, Geopolítica). 'Segurança' é um termo poderoso (SHEEHAN, 2005) cuja utilização tem consequências. "No other concept in international relations packs the metaphysical punch, nor commands the disciplinar power of 'security'" (DER DERIAN, 1995, p. 24-25). É um conceito ambíguo (WOLFERS, 1962), contestado (BOOTH, 2005; BUZAN, 1991), hifenizado (BUZAN; HANSEN, 2009), com fortes implicações políticas e ideológicas (BUZAN, 1991; DALBY, 1991; THOMAS, 1992). Suas características remontam às origens do conceito, justificadas pela "natureza esquiva do fenômeno que procura descrever" e pelos "esforços de diversos utilizadores no sentido de fixar e atribuir significados para os seus próprios fins" (DER DERIAN, 1995, p. 28).

Apesar de nuclear para os estudos de segurança o significado do conceito foi assumido acriticamente durante a Guerra Fria, isto é, não problematizado por aqueles que o utilizavam (BUZAN, 1991), o que justifica a adjetivação de conceito negligenciado (BALDWIN, 1997). O fato de o seu significado ter sido tomado como garantido num contexto em que dominava o paradigma realista e a investigação empírica (BUZAN; HANSEN, 2009), em detrimento da teorização, concorreu para o silêncio conceitual.

O fim da Guerra Fria estimulou o debate sobre a conceitualização da segurança. E, se num primeiro momento, a reflexão incidiu sobre a natureza da(s) ameaça(s), rapidamente se estendeu ao(s) objeto(s) referencial(ais) e ao(s) provedores(es) da segurança. Após os ataques terroristas de 11 de Setembro de 2001, destacou-se a preocupação sobre o nexo entre segurança interna e externa, abrindo espaço para uma fusão transdisciplinar progressiva e a categorização dos "nexos securitários" atrelada ao debate. 
O principal legado do debate foi o pluralismo teórico, metodológico e temático que hoje pauta a agenda de investigação dos Estudos de Segurança. Do alargamento ao aprofundamento, do racionalismo ao interpretativismo, do Realismo aos Estudos Críticos, novos conceitos, novas abordagens e novas temáticas emergiram, rompendo os silêncios teóricos, metodológicos e temáticos do período da Guerra Fria, pelo que hoje os Estudos de Segurança se afirmam como uma das subdisciplinas mais dinâmicas e em franca transdisciplinarização das Relações Internacionais (BRANDÃO, 2011).

\section{Ruptura Conceitual 3: A Transdisciplinarização através dos Nexos Securitários ${ }^{8}$}

O debate sobre a segurança resultou na tendência acadêmica e política para uma abordagem holística do fenômeno, confirmada pelo eixo de discussão chamado de nexos securitários no qual se evidenciam pelo menos três nexos: segurança-ambiente, segurança civil-militar e segurança interna-externa. No que diz respeito a este último, contrariando a separação entre "os dois braços do Príncipe", sustenta-se desde a dinâmica interativa entre ambos, na esteira do institucionalismo liberal, até a lógica de continuum no campo de segurança (BIGO, 2006a) e ainda a fusão das duas componentes da segurança (BIGO, 2006b). Esta linha de investigação holística desafia à criação teórica, reforçando o apelo à cooperação e síntese transdisciplinar, como demonstrado pela contribuição sociológica da "teoria do campo" de Bourdieu (THIRY-CHERQUES, 2006), que foi importado para os Estudos de Segurança.

Historicamente em "separate tables”, comunidades acadêmicas dedicadas ao fenômeno da segurança (Estudos de Segurança, Ciências Militares, Ciências Policiais), sentam-se hoje à mesma mesa da reflexão e debate científico, partilhando projetos de investigação, painéis de conferências e publicações. O apelo transdisciplinar inclui sociólogos, criminologistas, operadores do Direito, antropólogos, entre outros, o que leva alguns até a questionar a atual localização dos Estudos de Segurança como subdisciplina das Relações Internacionais.

\footnotetext{
${ }^{8}$ Versão adaptada de BRANDÃO, 2015.
} 
Ruptura conceitual 4: Segurança e Meio Ambiente em colisão ou coalizão?

A questão ambiental começou por ser politicizadaª, graças à crescente conscientização para a necessidade de proteção do ambiente e promoção de economias sustentáveis, tendo sido inserida nas agendas internacional e nacionais na década de 60 do século XX, avançado pelos anos 80 e estando sujeita a processos de securitização ${ }^{10}$ na década $90^{11}$.

Em 2004, o Relatório do Alto Painel da ONU em ameaças, desafios e mudanças (UNITED NATIONS HIGH-LEVEL PANEL ON THREATS, CHALLENGES AND CHANGE, 2004) incluía a degradação ambiental no primeiro cluster de ameaças coletivas (ameaças econômicas e sociais), relacionando-a com a pobreza e a doença.

Três anos mais tarde, o Conselho de Segurança das Nações Unidas realizou o primeiro debate sobre o impacto das alterações climáticas na segurança (UNITED NATIONS SECURITY COUNCIL, 2007) ${ }^{12}$. No mesmo ano, a segurança ambiental teve seu status aumentado na "agenda", tornando-se um "high-profile issue" (DALBY, 2013, p. 35), em grande parte devido ao relatório do Intergovernmental Panel on Climate Change que alertava para a gravidade do problema das alterações climáticas.

Em que pese a generalização do conceito de segurança, ainda prevalece a falta de consenso sobre o seu significado, quer na comunidade política quer na comunidade acadêmica. A polissemia é patente nas definições de segurança ambiental avançadas por Estados e por Organizações Internacionais. A produção acadêmica sobre o tema pauta-se não só pela diversidade e ambiguidade (BARNETT, 2001) como pela polarização (HOUGH, 2014).

\footnotetext{
9 "Politicization means to take an issue appear to be open, a matter of choice, something that is decided upon and that therefore entails responsibility" (BUZAN; WAEVER; WILDE, 1998, p. 29).

10 "[securitization] It is when an issue is presented as posing an existential threat to a designated referent object" (BUZAN; WAEVER; WILDE, 1998, p. 21). Aplicada ao ambiente, significa "treating issues such as pollution or resource depletion as threats meriting urgent and special political attention" (Hough, 2014, p. xiii).

11 Nota-se o precedente que remonta ao relatório da World Commission on Environment and Development, Our Commom Future (Brundtland Report), o qual relacionava ambiente e segurança.

${ }^{12}$ Cabe lembrar que, em 1989, o então Presidente da URSS, Mikhail Gorbachev, tinha proposta a criação de um Conselho de Segurança Ecológico à 46a Assembleia Geral das Nações Unidas.
} 
A propósito, uma das linhas da nova agenda de pesquisa é a da conceitualização da segurança ambiental. Outros tópicos são o processo de securitização, a segurança ecológica, segurança ambiental do Estado, a segurança ambiental humana ${ }^{13}$, a teorização sobre fatores ambientais em conflitos e a ligação entre questões ambientais e militares (BARNETT, 2001, p. 8). Esta última traduz-se no estudo da degradação ambiental provocada pela guerra, pela preparação da guerra (dimensão negativa ${ }^{14}$ ) e do papel dos militares na proteção do ambiente (dimensão positiva ${ }^{15}$ ). A dupla dimensão do nexo ambiente-militar está presente na narrativa da NATO que faz a distinção entre "proteção ambiental" - "[P]rotecting the physical and natural environment from the harmful and detrimental impact of military activities" - e "segurança ambiental" - "[A]ddressing security challenges emanating from the physical and natural environment" (NATO, 2014).

Em traços gerais, são identificadas três abordagens diferenciadas em função do objeto de segurança (BARNETT, 2016 apud COLLINS, 2016): ecossistema (análise do impacto da atividade humana nos ecossistemas); Estado (estudo da degradação ambiental ${ }^{16}$ como risco para a segurança nacional ou na sua relação causal com a conflitualidade inter- ou intraestatal'17); individuo (efeito das alterações ambientais na segurança humana $\left.{ }^{18}\right)$.

\footnotetext{
${ }^{13}$ O Relatório Anual do PNUD de 1994, intitulado Segurança Humana (SH), incorporava a segurança ambiental como uma das sete componentes da SH.

14 HOUGH (2014) considera quer os efeitos colaterais da atividade da guerra quer a destruição deliberada de recursos naturais ("ecocídio").

15 "In a number of countries military and intelligence assets are being used to collect environmental data and assist in the implementation of environmental initiatives such as reforestation. Military establishments throughout the world have met to discuss the threats posed by environmental degradation, share information and technology, co-operate in cleanup activities, and develop collaborative response mechanisms to environmental crises and conflicts. Often the defence community possesses skills and resources that may be the best available, at least in the shortterm, for various environmental tasks." (DABELKO; LONERGAN; MATTHEW, 2002, p. 5)

16 Na esteira de Barnett (2001, p.14), entendida como "processes by which the life-sustaining functions are disturbed."

17 "If a nation's environmental foundations are depleted,its economy will steadily decline, its social fabric deteriorate, and its political structure become destabilized. The outcome is all too likely to be conflict." (MEYERS, 1986 apud BARNETT, 2016 in COLLINS, 2016, p. 242),

18 "Physical changes in the environment are only one aspect of people's environmental insecurity, other factors are the extent to which people rely on the environment for their welfare, and the ability of people to adapt to environmental changes. (BARNETT, 2016 in COLLINS, 2016, p. 242).
} 


\section{Segurança ambiental versus segurança ecológica?}

Segurança ambiental e segurança ecológica não são faces da mesma moeda. Considerando o meio ambiente "como bem comum a todos" (LIMA; SHIRAISHI, 2015), o Antropoceno faz dessa separação uma importante bandeira, pois pode qualificar o papel antrópico e responsabilizar antes mesmo da degradação ambiental ou do fato ambiental doloso ou culposo consumado ou premeditado, através dos princípios da prevenção e precaução ${ }^{19}$.

O fato é que a espécie humana, "com as assimetrias relacionadas a países periféricos e dominantes, ricos e pobres, poderosos e desvalidos, converteu-se em uma força telúrica, um agente geológico global", transformando a Terra mais do que as atividades vulcânicas, forças tectônicas, ciclos e níveis de radiação solar ou alterações da órbita terrestre em torno do sol. A vulnerabilidade da natureza, sobre a qual não se suspeitava antes do Antropoceno, está sendo escancarada devido à extensão dos danos que se fizeram reconhecíveis (JONAS, 1995, p.32)

Entretanto, a crítica das ciências sociais, sob a forma de resistência às generalizações, é a de que o "Novo Regime do Antropoceno" já implica amplo poder para o homem (DE FREITAS, 2019). A mesma crítica assevera contribuições confiáveis a partir dessas resistências para o estado da arte da história política ambiental no sentido geopolítico ou geocrático. O ponto de vista é que o conceito do Antropoceno parte de um cenário em que "A Terra é vista como um sistema visto do nada onde há uma competição entre a espécie humana e o planeta" e da perspectiva de que as sociedades são "massas ignorantes e passivas que só podem ser guiadas por cientistas, despolitizando a história" (BONNEUIL; FRESSOZ, 2016).

Aprofundemos os seus contrastes. Em primeiro lugar, segurança ambiental distingue-se de segurança ecológica em função dos respectivos objetos

\footnotetext{
Diferenciam-se os dois princípios, porque o princípio da "precaução" é aplicável em situações onde existe incerteza científica acerca dos danos ambientais prováveis de uma determinada atividade e sua função seria a de ponderar as possibilidades. O princípio da "prevenção" abrange os casos onde há certeza científica sobre os malefícios ao meio ambiente.
} 
referenciadores. A segurança ecológica enfatiza, pelo menos implicitamente, que os processos ecológicos e os ecossistemas devam ser assegurados, que é uma referência prima face de um caráter não antropocêntrico. Assim, esta última parte do ecossistema como objeto referenciador, analisando os efeitos da atividade humana na segurança do ambiente, enquanto a primeira se reporta à degradação ambiental como ameaça/risco para a segurança do Estado (segurança nacional), dos grupos e indivíduos (segurança humana), sendo estes os objetos referenciadores (Estado, grupos, indivíduos) (BARNETT, 2001). Assim, insegurança ambiental é definida como "vulnerability of people to effects of environmental degradation", contemplando não só a dimensão física desta degradação como também a forma como esta afeta o bem-estar das pessoas (BARNETT, 2001, p. 17).

Segundo. A segurança ecológica propõe a criação de condições onde os entornos de uma comunidade provêm as necessidades de seus habitantes, sem diminuir seu estoque natural. Assim, a segurança ambiental refere-se mais à defesa de recursos naturais como efeito a uma negativa concepção prevalecente de segurança, enquanto a segurança ecológica se refere à segurança positiva que visa a manter o equilíbrio ecológico a longo prazo (ROGERS, 1997).

Terceiro. A segurança ecológica se sustenta a partir da visão cosmológica onde interdependência sistêmica, complexidade, incerteza, harmonia e sustentabilidade são palavras-chave. Isso clama por mudança no foco do indivíduo e na razão instrumental. Logo, ela oferece uma abordagem radical e mais ecocêntrica à segurança e seria uma tentativa de instrumentalizar o alto padrão de segurança para os propósitos ambientais (BROCK, 1992).

Quarto. A segurança ecológica pode oferecer mais do que simplesmente um levantamento do perfil de problemas ambientais. Incentiva atuação de ambientalistas mais centrados na Natureza. Farhi Neto (2006, p. 50) afirma que nos grupos ambientalistas considerados como moderados é o antropocentrismo que impera. "Os homens, iguais entre si e dotados de razão, estão no centro e a humanidade é, ao mesmo tempo, o sujeito e o objeto da história, da economia, do direito, da ética e da política, das relações internacionais". Os considerados radicais são ecocêntricos e descartam o antropocentrismo, "tendendo a repensar 
suas propostas a partir de uma descentralização em relação ao ponto de vista humano, incorporando a concepção de um modo de ser mais abrangente, indissociável da natureza”.

Na verdade, até os ambientalistas moderados querem algo diferente de uma visão instrumental majoritária aplicada como segurança ambiental e entendem que este conceito de segurança ecológica oferece alguma coisa a mais que o desenvolvimento sustentável não traz. Uma importante e frequentemente respeitada lição da ecologia é que os sistemas ecológicos estão constantemente em fluxos de curta duração e em mudança de longa duração. Usa-se isso como uma metáfora para repensar a mudança da política, argumentando que isso ajuda-nos a entender a sociedade como em perpétua mudança.

Quinto. A segurança ecológica valoriza a essência da resiliência, enquanto que a segurança ambiental a explora. Na teoria ecológica, a resiliência, que explica o caráter dos sistemas ecológicos, significa a propensão de um ecossistema a absorver em sua estrutura organizacional algumas perturbações. De uma certa forma é a habilidade de um sistema em recuperar-se depois de perturbações súbitas. A resiliência ecossistêmica é vista como função da complexidade das interações internas entre organismos, logo, quanto maior a interdependência e complexidade, maior a resiliência de um sistema às perturbações (HOLLING, 1973). Em termos gerais, espécies dentro de um ecossistema estão mais seguras quando um sistema é complexo e diverso. Fazendo a analogia com a segurança humana, a resiliência sugere que a segurança humana é função da diversidade social e que a segurança deveria ser no sentido de reduzir a vulnerabilidade à mudança e não resistir a mudança de per si (O’RIORDAN; RAYNER, 1991).

Existem outras implicações políticas e geográficas da teoria ecológica. Por causa da diversidade da complexidade dos processos biofísicos que compromete a totalidade da biosfera, a implicação para os sistemas humanos é a necessidade de um processo interdependente multifacetado e um cibernético sistema de intersegurança. Eckersley (1992), por exemplo, recomenda construirse uma estrutura política multidirecionada que muda de autoridade de uma comunidade a outra e que vai avançando de forma regional até um corpo global, onde a autoridade é alocada de acordo com necessidades especiais. 
Sem dúvida, uma visão ecológica de segurança sugere fortemente que a dominância formal da política do Estado-Nação é inapropriada, pela sua própria incapacidade gerencial20.

A noção de interdependência é central na teoria ecológica. Se os sistemas humanos e os ecológicos são fundamentalmente interdependentes, então, sugere-se que o desenho das fronteiras políticas que delimitam a soberania nacional é algo extremamente arbitrário ou que a terra não reconhece a soberania tal qual nós a conhecemos.

Essa imaginação geográfica alternativa, desafia o simplista e excludente modelo de série, de espaços políticos homogêneos e independentes definidos por fronteiras territoriais. Apesar desta desestabilização do ideal de soberania, entretanto, a noção não é tão fácil manipular. Westing (1989) e Byers (1991), que promoveram bioregiões também falharam na sua proposta, diante das complexidades extremas da soberania. Porque essas propostas omitiam a consideração da autonomia que é integral para a teoria e prática da soberania, eles não conseguiram resolver o dilema da independência e do mundo interdependente.

Ora, a soberania marca um complexo leque de direitos, alguns dos quais da não intervenção, que é fortemente afirmada contra certos clamores de que a interdependência necessita da supressão da soberania. Esse é certamente o caso de países com riquezas naturais que sofrem pressões de outros por esses recursos.

Exemplificando, o Brasil está dentre os países industrializados que utiliza desta propriedade da não intervenção em relação à Amazônia, porque não quer a disputa por estes recursos (CONCA, 1994). A resposta dos países estrangeiros ao Brasil é de estressar o sistema no sentido soberano de não intervenção como norma a ser preservada. E a soberania brasileira resiste aos argumentos da

\footnotetext{
${ }^{20}$ Usamos o critério analítico de Eckersley, que estabelece dois eixos: o do (1) antropocentrismo e o do (2) ecocentrismo. Cada eixo passa a ser polarizador de movimentos ambientais conexos, onde o primeiro relaciona-se com a articulação da teoria política que ofereça oportunidades para a emancipação humana e para uma sociedade ecologicamente sustentável e o segundo tende a valorizar o reconhecimento do mundo não-humano (TAVOLARO, 2001). Em nossa análise conceitual, a aplicação do conceito de segurança ambiental (antropos) está em um pólo e o conceito de segurança ecológica (eco) em outro.
} 
globalização que vêm de países mais adiantados (SARAIVA; SILVA, 2019), principalmente se a pressão é aplicada através de discursos ambientalmente orientados como o dos Estados Unidos, da Europa ou como resultado das imposições da regulação da economia global.

Sexto. Existe uma vulnerabilidade do conceito de segurança ecológica que é a de não fazer o que a segurança ambiental faz, que é exatamente a de contestar a terminologia e o terreno discursivo que a segurança nacional permite ao tema. É essa contestação que em parte faz a segurança ambiental válida. Em que pese a segurança ecológica ter muitas forças ao seu favor, ela falha na proposta de engajar efetivamente uma função fundamental para a segurança ambiental, que é a contestação e a deslegitimação da segurança por ela mesma (BARNETT, 2001).

\section{Discussão}

\section{Quanto à securitização e aos Complexos Regionais de Segurança}

Vejamos a confrontação de dois modelos: Primeiro modelo. Os complexos regionais de segurança (CRS) são uma teoria desenvolvida dentro da chamada Escola de Copenhague que deseja entender as questões de segurança internacional a partir de um enfoque regionalista. Por essa teoria, aprofundada por Buzan e Wæver (2003), os problemas de segurança estão mais intrinsecamente associados à sua região, mas continuam sofrendo a interferência da polaridade do sistema internacional e das tentativas de fusão.

Conforme Buzan e Wæver (2003), o CRS da América do Sul foi categorizado como padrão, e apresenta dois subcomplexos relevantes: o Cone sul e o Norteandino. Há uma maior estabilização da região, que tendia, após a Guerra Fria, a se distanciar de radicalismos, do controle político dos militares, com destaque especial para os processos de integração regional. Duas questões seriam importantes para o entendimento do CRS local: o futuro do Mercado Comum do Sul (Mercosul) e o combate às drogas na Colômbia.

Entrando dentro do Complexo Norte-andino, o Brasil foi o primeiro, dentre os países amazônicos dentro da Organização do Tratado de Cooperação 
Amazônica (OTCA) 21 , a criar uma estrutura institucional para a proteção ambiental, atrelando o mote ambiental à segurança regional.

Segundo modelo. Flemes et al. (2011) sustentavam a integração de uma comunidade de nações (chamava-a de Comunidade de Segurança). A União das Nações Sul-Americanas foi criada (UNASUL, em português'22) como resposta contra-hegemônica à proposta de constituição da Aliança de Livre Comércio das Américas (ALCA) (FARIA, GIOVANELLA; BERMUDEZ, 2015). Mas, a UNASUL erigiuse debaixo de uma especificidade ideológica antiliberal que trouxe resistências ao seu avanço, desde a sua criação, em um novo tipo de nacionalismo sulamericano (NERY, 2016).

Diante do fracasso desse modelo marcado pela prolongada crise no organismo, os governos do Brasil, da Argentina, do Chile, da Colômbia, do Paraguai e do Peru decidiram de forma conjunta suspender a sua participação na UNASUL. Em 2018, o governo federal brasileiro formalizou a saída do Brasil da UNASUL para integrar o Fórum para o Progresso da América do Sul (PROSUL).

Ato contínuo, o papel do Brasil seria o protagonista nessa manobra por uma reconstituição neoliberal das alianças no continente. Diferentemente da UNASUL, que surgiu em um momento em que os países tinham líderes de esquerda, o PROSUL apresentava o cenário oposto, surgindo em um momento de ascensão da direita na América Latina (SARAIVA; SILVA, 2019).

O processo de criação do PROSUL foi formalizado em Santiago, no Chile. Na ocasião, representantes de oito países sul-americanos - Argentina, Brasil, Chile, Colômbia, Equador, Paraguai, Guiana e Peru - assinaram a Declaração de Santiago, que traz os requisitos essenciais para integrar o fórum: estar em plena vigência da democracia, com respeito à separação dos poderes do Estado, liberdade e direitos humanos, assim como o respeito à soberania e integridade territorial. A proposta do PROSUL idealizada pelo Presidente chileno Sebastian

\footnotetext{
${ }^{21}$ Pode-se acessar através de http://www.otca-oficial.info/about/who_we_are o arquivo completo do Tratado de Cooperação Amazônica bem como o seu organograma. A visão, missão e objetivos estão em http://www.otcaoficial.info/assets/documents/20160702/2cda79262573e6f3840865e81d94fd82.pdf

22 O nome foi criado em 2007. Ver

https://web.archive.org/web/20071018022526/http://latercera.cl/medio/articulo/0,0,3255_5702 _263339850,00.html
} 
Piñera (mas tendo o Brasil como protagonista) tem formato mais flexível que a UNASUL: enxuto, menos oneroso e deve dedicar-se a iniciativas entre os países do bloco e ações conjuntas para o desenvolvimento da região. O espaço comum aborda, de maneira flexível, temas de integração em infraestrutura, energia, saúde, defesa, segurança e combate ao crime, e prevenção e manejo de desastres naturais.

Ainda não se tem evidências claras sobre como vai se desenvolver o PROSUL mas desde seu surgimento houve mudanças eleitorais nos países envolvidos. Por exemplo, a Argentina elegeu recentemente um governo de centro-esquerda, após o Ex-Presidente Macri não ter atingido as expectativas com seu governo. Outro aspecto que o PROSUL tem se deparado e que não houve reação integrada por parte do Brasil foi a questão das crises no Chile, na Bolívia, no Peru, no Equador. Talvez seja cedo demais culpabilizar-se a organização ou melhor caracterizá-la no desdobramento de suas políticas públicas regionais comuns, que apontam para uma institucionalidade prevista (FORTI NETO, 2020). A antiga iniciativa para a Integração da Infraestrutura Regional Sul-Americana (IIRSA) na ideia de interligar os oceanos Atlântico e Pacífico por meio de rodovias ou ferrovias que atravessassem a região ("corredor bioceânico"), incentivada pelo Presidente Evo Morales em 2006 teve seu contraponto com o novo posicionamento de Bolsonaro no PROSUL ao aproximar-se do Chile. Sebastian Piñera, que também estivera na posse de Bolsonaro, anunciou a execução do corredor bioceânico rodoviário que exclui a Bolívia. Enquanto Evo Morales ${ }^{23}$ buscava apoio do Peru e do Paraguai, o Brasil, na sua nova concepção de integração aberta latinoamericana para o PROSUL (ARAÚJO, 2019) juntamente com o Chile, propôs um corredor rodoviário bioceânico cuja rota isola a Bolívia.

Mesmo com um espaço comum maleável por um alinhamento econômico-ideológico de desenvolvimento regional, há crítica de que a integração sul-americana avança alicerçada em bases frágeis, com uma forte retórica nacionalista, defesa da soberania e de não intervenção. São princípios

\footnotetext{
${ }^{23}$ EVO Morales toma posse como primeiro presidente indígena na Bolívia. Folha de S. Paulo, São Paulo, SP, 22 jan. 2006. Disponível em:

https://www1.folha.uol.com.br/folha/mundo/ult94u91812.shtml. Acesso em: 23 mar. 2021.
} 
importantes, ainda com indicadores insuficientes para formar uma comunidade de segurança, mas que apontam para a formação de um único complexo regional de segurança em direção a um modelo centrado (FUCILLE; REZENDE, 2013). A retórica permanece a mesma principalmente no caso do Brasil, e há um moroso vai e vem no processo de integração regional sulamericana. Em 2021, a pandemia do SARS Cov 2, os desmatamentos e incêndios na Amazônia permanecem como desafios à integração e à OTCA.

Uma hipótese foi levantada de que, sendo unipolar na região, e a partir de um papel protagonista aquiescido pelos Estados Unidos da América (EUA) em nível global, ainda que vacilante, o Brasil tem um papel de centralizador dos subcomplexos do norte-andino e do cone sul. Deve-se considerar que, mesmo que o papel do Brasil possa ser oscilante enquanto liderança geopolítica na América do Sul, suas iniciativas preliminares são suficientes para a agregação desses dois subcomplexos sul-americanos. Isso faz com que o CRS regional seja descrito como centrado, em que a potência unipolar não é uma potência global, inaugurando, assim, um primeiro caso empírico desse tipo de CRS. É nesse ponto que um complexo regional de segurança se difere de uma comunidade de segurança: para o primeiro, não é necessário que as relações sejam harmoniosas, mas sim que as dinâmicas de segurança da região sejam centralizadas em um único ator. Ainda que o Brasil careça de maturidade como fiador das instituições regionais, todas as principais dinâmicas de segurança da região têm passado, de alguma forma, sob a égide brasileira (FUCILLE; REZENDE, 2013).

O espaço do PROSUL exemplifica (dentre outros espaços de formação de blocos de alianças internacionais) e abriga o esforço de securitizar as disciplinas envolvidas no processo, que constituem novas fusões que se consolidam em novos temas como segurança energética limpa, segurança sanitária e dos alimentos, segurança, defesa e combate ao crime com avanços em tecnologia 5G e com aprimoramento da inteligência artificial e robótica aplicada à segurança, segurança eletrônica para os sistemas de informação e bases da dados e da integração securitária com a resiliência individual, comunitária e nacional. Com tais fusões transdisciplinares em curso, cabe uma nova leitura das perturbações sistêmicas que reconhecem incertezas e indeterminações em um campo da 
segurança em reconstrução questionando sua própria securitização no Antropoceno.

\section{Quanto à transdisciplinarização}

Partindo da hipótese de o Brasil ser o líder compulsório do Complexo Regional de Segurança (geopoliticamente enfatizado) ou da Comunidade de Segurança (ideologicamente enfatizado) da América do Sul, sua importância enquanto ator nas relações internacionais é preponderante para o equilíbrio de poder na região amazônica e no comprometimento ambiental dos seus recursos naturais, mas ainda tal papel vêm marcado pelo nexo segurançadesenvolvimento. Apesar de colocarmos um conjunto de conceitos em oposição para testarmos suas incompatibilidades no campo de segurança e meio ambiente, permanece o dilema de segurança do meio ambiente representado pelas relações conceituais ambíguas e pelas diferentes realidades contextuais da segurança ambiental e da segurança ecológica e, por fim, estamos diante de uma fusão histórica dos nexos de segurança e desenvolvimento com o de meio ambiente em curso.

Vejamos a contextualização disso. Desde a segunda grande guerra (II GM), uma das ideias americanas (EUA) para emancipação do bloco ocidental foi a da internalização do conceito de segurança nacional, ou seja, o comunismo passaria a ser visto não como ameaça de uma nação inimiga, mas como um inimigo interno que manipularia as tensões sociais existentes em um país em benefício de sua ideologia e de acordo com os interesses de uma nação inimiga.

Ali inferia-se a preocupação de associar-se segurança ao desenvolvimento que aponta para a melhoria das condições de segurança nacional através do desenvolvimento global da nação. Sob tal ponto de vista, era necessário repensar o problema nacional também em conjunto com..."civis de notável competência e atuação relevante na orientação e execução da política nacional..." (BRASIL, 1949), fato que é cuidadosamente mencionado no regulamento da Escola Superior de Guerra (ESG) e que provoca a estreita cooperação entre militares e civis escolhidos para o desempenho confiável de aprimorar a metodologia para 
a formulação e planejamento da Política Nacional de Segurança e Desenvolvimento.

A proposta de segurança e desenvolvimento necessitava ser desenvolvida de forma orquestrada com a participação de agentes sociais modernizanteconservadores, considerados "intelectuais orgânicos" adaptados pelo modelo de Antonio Gramsci (SEMERARO, 2006) do novo bloco em formação no ambiente da guerra fria. A estrutura política formada do bloco multinacional estava consolidada em uma intelligentsia empresarial. A composição deste grupo seleto era, de forma geral: a) diretores de corporações multinacionais; b) administradores de empresas privadas, técnicos e executivos estatais que faziam parte da tecnoburocracia; e) um restrito grupo de oficiais do Exército. Tais componentes representariam o que René Armand Dreifuss (1981) caracterizaria como uma associação de militares e civis que comporiam o "braço militar-tecnoburocrático", que vemos como uma fusão do aparelho ideológico da guerra fria.

Havia um grau de convergência de afinidades desses oficiais com Lucas Lopes, Roberto Campos, Eugênio Gudin e Octávio Gouveia de Bulhões que compartilhavam as salas de aula da ESG, como conferencistas. Na verdade, havia um espaço bem demarcado de cumplicidade na difusão das ideias desenvolvimentistas, pois a corrente militar da ESG, conforme aponta Dreifuss, "compartilhava com os interesses multinacionais e associados tanto a perspectiva quanto o sentido de urgência em transformar o ritmo e a orientação do processo de crescimento em direção à criação de uma sociedade industrial capitalista” (DREIFUSS, 1981, p.78).

Existe um outro componente que colabora para intensificar a predileção de alguns desses oficiais pelo mecanismo burocrático-industrial: a participação militar de oficiais na iniciativa privada nas décadas de 1950 e início da de 1960 se via como direção de cargos empresariais ou no controle acionário de empresas ${ }^{24}$,

\footnotetext{
${ }^{24}$ Bolsonaro recentemente nomeou um general da Reserva do Exército para a presidência da Petrobrás (2021), revelando fenômeno semelhante ao aparelhamento demonstrado por Dreifuss, 1964. Boa parte das Forças Armadas brasileiras está defendendo a questão nacional pela via dos costumes, da tradição, da identidade que estaria ainda sob ataque comunista no modelo realista da Guerra Fria. No plano econômico, a identidade e a nacionalidade seriam sustentadas pelo mercado, sobretudo pelos capitais estrangeiros (de preferências norteamericanos) que supostamente trariam a modernidade para o país. A lógica seria da altivez na identidade cultural, mas da submissão ao plano econômico do governo federal, respeitando-se a hierarquia e a disciplina.
} 
permitido após o acordo militar de 1952 entre o Brasil e os EUA. Para ambientar o aparecimento das primeiras ações do Projeto-ESG, marcadas pela fervura política dos anos 50, é interessante notar o que diz Vanda Aderaldo (1978, p. 8485) no tocante ao papel da Escola. Para ela, a então criada Escola Superior de Guerra (ESG) "estaria comprometida com um determinado diagnóstico da situação brasileira e com o propósito de modificar essa situação através do direito, assumido pelos militares, de intervirem num processo pouco preciso de desenvolvimento do potencial geral da Nação", como pré-condição para a sua tarefa específica de garantir a segurança nacional (ADERALDO, 1978).

A existência da ESG, portanto, pareceria não fazer sentido, caso se negasse às forças armadas o direito de intervir no processo de desenvolvimento do potencial da Nação. Na verdade, o objetivo da ESG, enquanto instituição militar de ensino, era instrumental. A nova tarefa de garantir a segurança hemisférica se dava dentro de um esforço doutrinário (ideológico de cunho bipolar, na época) de integração que estava situada no âmbito da política externa e surgida dentre as relações do Brasil com os Estados Unidos, no período pós-guerra. E ela exigiria um tipo de preparo formal dos militares para uma função com dimensões politicamente institucionalizadas. Por outro lado, a socialização dos civis também era necessária na compreensão de que essa tarefa, devido às circunstâncias de ameaça de guerra iminente, deveria ser realmente das forças armadas.

O desafio para a proposta de segurança nacional mesclada com desenvolvimento foi trazer à equação outro fator importante: o meio ambiente, até então não intelectualmente concebido e ainda não contemplado como parte do planeamento estratégico. Naturalmente, o fator meio ambiente direcionava as preocupações para a Amazônia.

$E$, no tocante a isso, precisa-se novamente mencionar o Brasil, neste concerto de nações. O Brasil possui a maior percentagem de floresta (úmida e com mega diversidade biológica), um solo e subsolo com imensas reservas

\footnotetext{
Sobre a nomeação de um general do exército para a Petrobrás, ver https://www.diariodepernambuco.com.br/noticia/politica/2021/02/bolsonaro-demitepresidente-da-petrobras-e-nomeia-general-para-o-cargo.html. Acompanhar o momento através do caminho aberto por MATHIAS, Suzeley Kalil. A militarização da burocracia: a participação militar na administração federal das comunicaçőes e da educação, 1963-1990. Unesp, 2003.
} 
estratégicas minerais, tem antecedentes históricos de ocupação e de desenvolvimento econômico regional (ANDRADE JÚNIOR, 2018) e ainda hoje tem posicionamento mencionado, tanto no nível regional como global, da aspiração de estar dentre os principais Estados em assuntos internacionais.

A repercussão internacional sobre o meio ambiente e a ação consequente para os efeitos humanos causados na natureza foi marcada pela Conferência das Nações Unidas sobre o Meio Ambiente Humano, na Suécia, em 1972. O evento trouxe ao campo do estudo de segurança o meio ambiente como foco de análise. A posição do Brasil em relação às questões ambientais colocadas pela conferencia, endossada pelos demais países do chamado Terceiro Mundo, foi bastante clara: o crescimento econômico não deveria ser sacrificado em nome de um ambiente mais puro. Os delegados brasileiros até reconheceram a ameaça da poluição ambiental, mas sugeriram que os países desenvolvidos deveriam pagar pelos esforços dessa purificação. Além disso, o Brasil discordou da relação direta entre crescimento populacional e exaustão dos recursos naturais, opondose fortemente às propostas de medidas de controle de natalidade_(FERREIRA, 1998).

Na lógica que seria multiplicada nos anos seguintes, a discussão sistêmica sobre os efeitos da relação homem/natureza trouxe aos Estados Nacionais um desafio na formulação de suas políticas. Se, por um lado, os efeitos sobre o meio ambiente eram de ordem territorial que ultrapassam as fronteiras nacionais, por outro, o uso da natureza era encontrado nos Estados que reivindicavam soberania sobre o uso de seu território. Leff (2001) afirmara que uma racionalidade ambiental implica na transformação de conceitos e métodos das ciências e dos campos disciplinares do saber, de valores e de crenças sociais na direção da Natureza. Tais transformações ideológicas e epistêmicas não são efeitos traçáveis a partir do posicionamento de diferentes classes sociais, mas implicam na análise de processos complexos (LEFF, 2000) que colocam em jogo os interesses institucionais e de diferentes grupos de poder em relação à apropriação dos recursos naturais. Ora, a racionalidade ambiental evidenciava princípios materiais e axiológicos do discurso ambientalista que seriam 
interessantes para contracenarem com os movimentos que reincorporavam os valores da natureza e da democracia participativa diante do militarismo.

O conceito dessa racionalidade ambiental funcionaria como um sistema de valores, normas, ações e relações de meios e fins, que permitiria analisar a coerência de um conjunto de processos sociais que se abrem para a construção de uma teoria da produção e da organização social fundada nos princípios de ecodesenvolvimento, da gestão ambiental e do desenvolvimento sustentável (LEFF, 2001).

Nesta nova discussão sobre o meio ambiente, a maior floresta tropical do mundo, a Amazônia, seria ainda mais proeminente, tendo uma história de colonização e de conquistas épicas e despertando agudo interesse mundial por ser a última fronteira de recursos, sobretudo naturais e minerais (ANDRADE JÚNIOR, 2018). Bertha Becker (1998), uma importante pesquisadora (com mais de quarenta anos pesquisando a região amazônica brasileira) e consultora ad hoc mundial em muitas situações foi favorável, desde o início do lançamento do conceito de desenvolvimento sustentável (DS) em meados de 1990, à possibilidade de usá-lo na região, mas também trouxe uma cautela. Becker afirmara que o DS seria usado como instrumento político, reconhecendo que ele não se resumia à harmonização da relação entre a economia e a ecologia e que também não era uma questão técnica: representava um mecanismo de regulação do uso territorial que tentava ordenar a desordem global e, portanto, confirmara o nexo segurança-ambiente-desenvolvimento na discussão amazônica.

Devido a esse interesse que estava se explicitando especialmente após a Conferência mencionada, os países amazônicos reforçaram suas agendas para essa região, temendo o discurso da internacionalização e da soberania estreita dos países desenvolvidos. Recentemente, a discussão Europa-Brasil ressaltou o discurso recorrente nacionalista e soberanista (SARAIVA; SILVA, 2019). Na disputa por interesses regionais, o Presidente brasileiro (Jair Bolsonaro), em discurso na Assembleia Geral da ONU, acusou Emmanuel Macron (Presidente francês) de ceder à ação de lobbies franceses contrários ao Acordo Mercosul-EU (BULLA et al., 2019). 


\section{Cenários conceituais emergentes}

Pode-se identificar dois cenários conceituais quanto à segurança (com suas aproximações e distanciamentos) no debate sobre a natureza da ameaça.

O primeiro cenário refere-se ao momento do pós-segunda guerra mundial até o término da guerra fria (anos 50-90 do século XX), em que a configuração de poder mundial vai tomando forma, tendendo para a bipolaridade. Nesse cenário, a doutrina dos países líderes na polarização estará se afirmando e percebe-se o pressuposto da segurança ativado por uma inquietude de ameaça e de ausência de debates conceituais críticos do campo da segurança de per si, de forma intrínseca. A preocupação com o desenvolvimento e a segurança nacional é influenciada diretamente pelo esforço na equilibração do poder (Figura 1).

O segundo cenário refere-se ao momento posterior ao término da guerra fria (anos 90 em diante), em que as reflexões sobre segurança passam a ter um caráter mais crítico, de menor "patrulha" da afinação ideológica, na busca por uma resolução de conflitos, da sustentabilidade, depois de um balanço centrado nos impactos trazidos pelo cenário anterior e da iminência de novos conflitos de ordens diversas na reconfiguração de poder multipolarizado (figura 2).

Figura 1. Cenário conceitual dos nexos securitários desde a segunda guerra mundial até

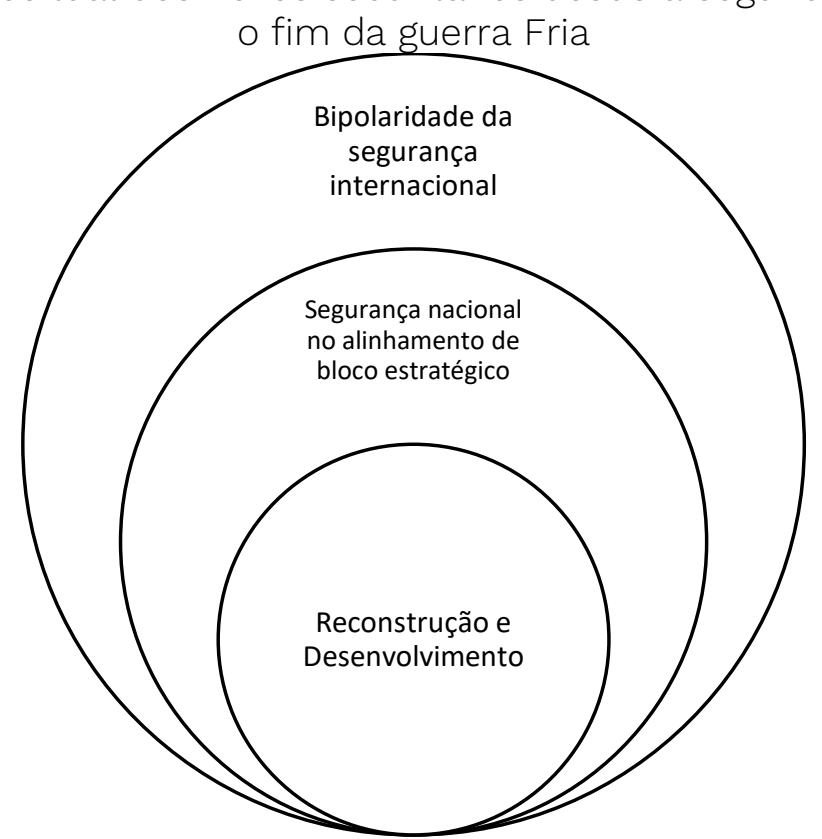

Fonte: elaborado pelos autores, 2021 
Figura 2. Cenário conceitual dos nexos securitários desde o término da guerra fria

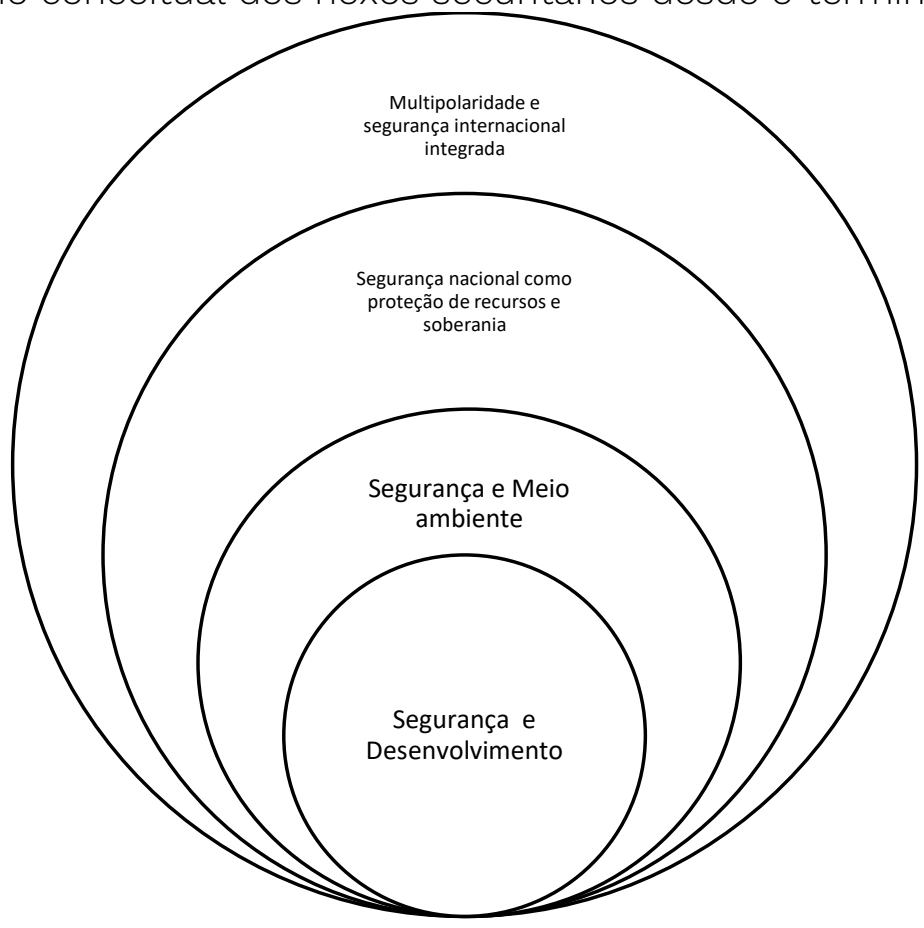

Fonte: elaborado pelos autores, 2021

\section{Quanto às rupturas conceituais de segurança no Antropoceno}

\section{Ruptura conceitual 1}

No debate sobre a segurança (compreendido no campo das Relações Internacionais) desde o pós-Guerra Fria percebe-se que o estado Westfaliano está menos espaçoso. A questão geral é que tais elementos constitutivos da transformação estão afetando o cerne do Estado (o território), prejudicando sua integridade. Bertha Becker (1994) já explicara que do ponto de vista da lógica da dominação, a revolução tecnológica na microeletrônica e na comunicação está criando novas estruturas de relações espaço/tempo e, portanto, pondo abaixo aquela resolução de conter a comunidade política no espaço do Estado; de conter o tempo; da mudança como progresso linear, dentro do Estado. A velocidade, no mundo contemporâneo, tornou-se elemento chave capaz de alterar as formas de produção, as relações sociais e as relações de poder, assim como a velocidade viabilizada através das redes técnicas permitem a difusão instantânea da informação, provocando o encolhimento do espaço. 


\section{Ruptura conceitual 2}

Nas aproximações e distanciamentos conceituais sobre os estudos de segurança que são cabíveis ao modelo do Antropoceno, novas temáticas seriam consideradas para a continuidade de alargamento do debate. Citamos algumas. Temática 1. Há inúmeros fatores e evidências de contaminação, de manipulação genética e de alterações climáticas ligadas à ação do ser humano na Natureza. A Natureza (o sistema da Terra) apresenta muitas dificuldades para recuperar-se destes agravos, com os quais muitas espécies já foram extintas. Temática 2. 0 ser humano não teria conseguido garantir a sustentabilidade da vida e do ambiente, com a qualidade que se necessita e que dele depende. Temática 3. A segurança do território e das populações dependeria de ajustes nesses fatores e nas regras de governança. Temática 4. Resiliência, educação ambiental e competência ambiental seriam meios conceitualmente aprovados de prevenção de desastres e catástrofes e poderosos instrumentos de gestão.

\section{Ruptura conceitual 3}

Ainda que os Estudos de Segurança estejam dentre as mais dinâmicas disciplinas das Relações Internacionais, questiona-se que este dinamismo permita resultados favoráveis quanto à discussão transdisciplinar para a reversão de fenômenos ou de agravos ambientais apontados pelo Antropoceno. Vamos marcar isso.

Primeiro. A transdisciplinarização através dos nexos securitários implica em valorizar a proposta transdisciplinar que afirma que a realidade da vida não é fragmentada, nem dividida em disciplinas e que uma educação de qualidade requer um ensino que envolva a compreensão do ser, da vida, da cultura, em suas relações e inter-relações. A ação transdisciplinar do autoconhecer-se (NICOLESCU, 2000) é tão importante que conhecer e discutir ideologias e conceitos no que tange à segurança em todas as suas ramificações e nexos possíveis.

Ações transdisciplinares no Antropoceno quanto aos estudos de segurança poderiam evidenciar novas técnicas e metodologias para a reversão da degradação e mitigação ambientais. Santos Neto (2006) afirma que o trabalho 
com o corpo, saber lidar com as emoções, com a razão e com o espírito, desenvolver a consciência ecológica, o respeito pelas diferenças pessoais, coletivas e raciais, saber transitar entre o mundo da interioridade e da exterioridade sócio-político-econômica, ainda seriam boas opções que ajudariam a considerar microrrealidades onde todas as dimensões estão interligadas.

Segundo. Morin (2010) afirmaria que reformar um pensamento é um problema paradoxal, uma vez que para reformar o pensamento é necessário, antes de tudo, reformar as instituições que permitem esse novo pensar. Mas para isso, seria necessário que já existisse um pensamento renovado e então o dilema a ser vivido seria o da reeducação dos educadores: um marco de um novo paradigma voltado para a reforma do pensamento. Na prática, a proposta seria uma oportunidade que melhoraria o processo de ensino aprendizagem, tornando as aulas (que permitem as trocas conceituais com a consequente discussão e exame de rupturas) mais atraentes e eficientes, englobando todas as disciplinas, articulando-as com as inúmeras faces de compreensão do mundo e suas microrrealidades. Assim, rompe-se (estariam ainda mais acessíveis os exames da ruptura em si para o Antropoceno) com o processo tradicional no qual a educação era restrita a conceitos pré-determinados e incontestáveis, pois no pensamento transdisciplinar as disciplinas não são mais abordadas de modo fragmentado e isoladas das demais, tornando natural um compartilhamento de ideias, pensamentos e opiniões.

\section{Ruptura conceitual 4}

A construção do nexo transdisciplinar de segurança e meio ambiente é repleto de desafios por parte da comunidade acadêmica dos estudos de segurança, que, para fins de exame do Antropoceno, deveriam constituir-se de equipes de trabalho transdisciplinar atuando em redes integradas e em consórcios científicos internacionais, uma vez que a hipótese de ameaça global crescente do Antropoceno aponta para que o tema da segurança seja absolutamente central e prescritivo diante das outras ciências.

Por exemplo, as relações de segurança com a crise ambiental podem estar qualificadas em dois níveis: (1) o da funcionalidade, dinâmica, respeito e proteção da natureza, considerando o sistema da terra (geologia, geofisiologia, geofísica, 
oceanologia, glaciologia, sismologia, astronomia, astrofísica...), o ontológico da natureza e suas particuliaridades (habitat, biomas, biota, ecossistemas, diversidade biológicas locais interagentes, autoorganização...), mais adequado ao conceito de segurança ecológica e (2) o de uso da natureza com predominância da exploração da fronteira de recursos, como nichos ecológicos a serem explorados para uso humano, enquadrado pela conceituação de segurança ambiental.

Entretanto, não é muito peculiar, no arcabouço teórico das relações internacionais contemporâneas, lidar com o primeiro nível, uma vez que demanda tratos e conhecimentos da ciência da Terra e da Natureza, pressupondo uma articulação interdisciplinar de saberes para incorporar ao discurso ou à formulação de politicas publicas e decisões. O segundo nível está imanente na noção de Segurança Internacional e é historicamente marcado pela Segurança Nacional, funcionando como regulador das relações de poder e de interesses entre Estados e Blocos, tratando-se obviamente dos limites da exploração dos recursos e das responsabilizações condizentes entre os atores.

\section{Considerações Finais}

Através deste ensaio teórico, procurou-se alargar a discussão sobre os Estudos de Segurança do pós-Guerra Fria, examinando a sua intensificação de forma crítica. Vimos sua conceitualização, acompanhamos a transdisciplinarização e a própria tendência de securitização, estudando cenários, atendendo ao apelo do Manifesto de Burke et al. (2016) no tocante aos limites das Relações Internacionais no contato com o conceito do Antropoceno.

Viñuales (2016) ${ }^{25}$ afirmara que o Antropoceno, para além de sua origem na estratigrafia terrestre, é uma narrativa dotada de autonomia indicada por duas razões: a) apesar de muitas interpretações e usos, o termo tem um núcleo recorrente, qual seja o de que a Terra vem sendo remodelada pelos humanos como uma força de proporções geológicas ou, mais especificamente, os seres

\footnotetext{
${ }^{25} \mathrm{Em}$ seu artigo sobre o Antropoceno, Viñuales introduz as bases de uma pesquisa profunda e crítica sobre a chamada "Narrativa do Antropoceno" (Ver mais em VIÑUALES, Jorge. Law and the anthropocene. 2016)
} 
humanos (melhor dizendo, alguns humanos) efetuaram irreversíveis mudanças no sistema da Terra; b) o Antropoceno serve como uma plataforma para coligar todos os grandes temas do momento: capitalismo, militarização, crenças religiosas, etc. Assim, “todos os corpos do conhecimento sobre o mundo" são chamados a refletir sobre o Antropoceno (MARCHESAN, 2019, p.46).

O Antropoceno prenuncia uma época de insegurança. Embora a atenção à segurança tenha crescido nas últimas duas décadas em um franco estímulo ao debate pós-guerra fria que tem um processo de securitização visivelmente instalado no sistema global, persiste um grande número de nexos de segurança em construção transdisciplinar que merecem reexame crítico diante do fenômeno da degradação ambiental criada dentro do Antropoceno conceitual e que defende uma ameaça bipolar humano-natureza a partir das Geociências. O modelo está sendo criticado por suas prerrogativas generalistas e excludentes por historiadores, cientistas sociais, antropólogos que já haviam estudado a questão ambiental em seus dilemas binários de oposição (como ACSELRAD, 2010; MOSLEY, 2006) e também agora por pensadores das relações internacionais (BURKE et al., 2016).

Percebemos que rupturas no campo conceitual de segurança estão instaladas, tem nexos observáveis marcados pela história a ponto de sermos provocados a sugerir um locus acadêmico transdisciplinar e transversal que rompa com tradições metodológicas e epistemológicas, através da estranheza dos fenômenos críticos a estudar.

Exemplificado de forma breve o cenário pouco provável de integração de Estados na América do Sul, chamamos a atenção para o papel preponderante do Brasil como ator unipolar, em um caso ímpar na literatura. Também sinalizamos que, com o aumento da preocupação com as alterações climáticas, qualquer descompasso na Amazônia passa a ser de vital importância global. Essas mudanças têm sido acompanhadas e defendidas por pesquisadores e alguns deles realmente acreditam em uma nova era geológica (WATERS et al., 2016; ZALASIEWICZ et al., 2016) canalizada no Antropoceno, marcada pela industrialização e pelo crescimento das atividades produtivas humanas (STEFFEN; BROADGATE; DEUTSCH, 2015). 
Como o Estado não pode lidar mais com os seus problemas ambientais de forma exclusiva em seu território, instituições devem ser competentes e responsáveis dentro de suas fronteiras e além delas. Este é trabalho das relações internacionais, que é confrontado como uma outra epistemologia do pós-Guerra Fria em que fronteiras nacionais pouco significam para os temas ambientais, uma vez que estão relacionadas a todo o sistema da Terra e do Cosmos. Outro aspecto é que, limitado pelo espaço, o militarismo assim prossegue dentro de Estados limitados como uma razão atemporal. Dessa forma, além de conhecer mais o trabalho dos militares, a sociedade precisa ser alcançada pela estrutura íntegra e competente da defesa civil e da proteção civil na gestão do território, uma vez que dependerá disso para proteger-se de ameaças ambientais, sempre complexas e que não são de ordem realista como no período da Guerra Fria.

No pós-Guerra Fria, o trend dominante é do conflito intraestatal. Na América do Sul, a guerra regional apresenta baixa probabilidade de acontecer. Quanto ao Brasil, que esteve envolvido em uma guerra com seus vizinhos pela última vez há cerca de 150 anos (a Guerra do Paraguai), essa possibilidade se aproxima de zero. Essa percepção levou analistas a se perguntarem se a região geográfica da integração sulamericana, deixada sem inimigos externos claros, deveria manter suas Forças Armadas, sugerindo a transferência dos recursos orçamentários federais para áreas de infra-estrutura, saúde pública e educação, de que tanto necessitam. Mas, há uma posição contrária que não é única. Ugarte, por exemplo, argumenta que "[n]enhum Estado que possua um patrimônio territorial e material apreciável renuncia a defendê-lo com Forças Armadas proporcionais à sua capacidade econômica de sustentá-las" (UGARTE, 2001, p. 29).

A defesa da Amazônia posterga uma clara definição do novo papel dos militares, já que reforça seu papel convencional ao identificar claramente uma ameaça externa - a guerrilha e a entrada no território brasileiro de traficantes de droga estrangeiros, dentre outros tantos ilícitos e cujo Sistema de Vigilância da Amazônia (SIVAM) os mantém bem motivados (ANDRADE JÚNIOR, 2018). Há uma certa recorrência no modelo de segurança internacional da Guerra Fria, porque a defesa da Amazônia, além do mais, ainda enfatiza o preparo e o emprego do 
modelo da Guerra Fria que requer largos contingentes militares e, com isso, justificam o serviço militar obrigatório. Ali, os militares identificam também como inimigo interno algumas ONGs estrangeiras que atuam na preservação ambiental e de terras indígenas (ANDRADE JÚNIOR, 2018; SANTOS, 2004).

Cabe ressaltar que militares não atuam somente em tempo de guerra e podem compartilhar seus recursos, tecnologia e expertise para mitigar os agravos anunciados pelo Antropoceno, ampliando as relações civis-militares nas questões ambientais. Nesta direção, caberia a exploração de linhas de investigação que ressignifiquem e que facilitem a transdisciplinarização do campo dos Estudos de Segurança nas temáticas dos sistemas integrados civismilitares; da ampliação dos estudos e da competência ambiental dos militares e da população em geral; da interação da cultura organizacional militar com a população, para mitigar insatisfações, ansiedade e medo diante de novos agravos ambientais; da provável criação de unidades militares a serem treinadas para agravos ambientais com consciência ecológica e com plano estratégico geral de gestão ambiental e de contingência; da educação ambiental transversal obrigatória nos currículos militares; e da sua integração com os Estudos de Resiliência (militares e civis, nas dimensões individual, social, nacional).

\section{Referências}

ACSELRAD, Henri. Ambientalização das lutas sociais: o caso do movimento por justiça ambiental. Estudos Avançados, São Paulo, v. 24, n. 68, p. 103-119, 2010.

ADERALDO, Vanda. A Escola Superior de Guerra: um estudo de currículos e programas. Dissertação de Mestrado. Instituto Universitário de Pesquisas do Rio de Janeiro, 1978. Mimeografado.

ANDRADE JÚNIOR, Hermes. Autoethnography (military, environment) as transdisciplinarization in Anthropocene times. Cultural Studies $\leftrightarrow$ Critical Methodologies, Champaign, p. 1-13, 2020.

ANDRADE JÚNIOR, Hermes. Segurança e proteção da Amazônia em tempos de crise e escassez: um estudo de caso / security and protection of the Amazon in 
time of crisis and shortage: a case study. Revista de Direito da Cidade, Rio de Janeiro, v. 10, n. 3, p. 1380-1421, 2018.

ARAÚJO, Ernesto. Intervenção do Ministro Ernesto Araújo na VIII Reunião do Corredor Rodoviário Bioceânico. In: DISCURSOS. Campo Grande: Itamaraty, 22 ago. 2019. Disponível em http://www.itamaraty.gov.br/pt-BR/discursos-artigoseentrevistas-categoria/ministro-das-relacoes-exteriores-discursos/20764intervencaodo-ministro-ernesto-araujo-na-viii-reuniao-do-corredor-rodoviariobioceanico-campogrande-ms-em-22-de-agosto-de-2019. Acesso em: 10 set. 2019.

BALDWIN, David A. The concept of security. Review of International Studies, Cambridge, v. 23, n.1, p. 5-26, 1997.

BARNETT, Jon. The meaning of environmental security: ecological politics and policy in the new security era. London: Zed Books, 2001.

BECKER, Bertha K. A (des)ordem global, o desenvolvimento sustentável e a Amazônia. In: BECKER, Bertha K. (org.). Geografia e meio ambiente no Brasil. 2. ed. São Paulo: Annablume: Hucitec, 1998. p. 46-64.

BECKER, Bertha K. Estado, nação e região no final do século XX. In: A AMAZÔNIA E A CRISE DA MODERNIZAÇÃO. Belém-PA: MPEG, 1994. p. 103-109.

BELCHER, Oliver; SCHMIDT, Jeremy. Being earthbound: Arendt, process and alienation in the Anthropocene. Environment and Planning D: Society and Space, Santa Barbara, v. 39, n. 1, p. 103-120, 2021.

BIGO, Didier. Globalized (in)security: the field and the ban-opticon. In: SAKAI, Naoki; SOLOMON, Jon (eds.). Translation, biopolitics, colonial difference: Aberdeen. Hong Kong: University of Hong Kong Press, 2006a. p. 109-156.

BIGO, Didier. Internal and external aspects of security. European Security, London, v. 15 n. 4, p. 385- 404, 2006b.

BONNEUIL, Christophe; FRESSOZ, Jean-Baptiste. The shock of the Anthropocene. London: Verso Books, 2016.

BOOTH, Ken. Critical security studies and world politics. Boulder: Lynne Rienner Publishers, 2005.

BRANDÃO, Ana Paula. The internal-external nexus in the security narrative of the European Union. JANUS.NET, Lisboa, v. 6 n. 1, 2015. Disponível em: http://observare.ual.pt/janus.net/en/previous-issues/327-vol-6,-n-1-mayoctober-2015. Acesso em: 13 dez 20.

BRANDÃO, Ana Paula. Vinte anos depois: mapeando o quadro teórico e a agenda de investigação dos Estudos de Segurança". In: CONGRESSO 
OBSERVARE “TENDÊNCIAS INTERNACIONAIS E POSIÇÃO DE PORTUGAL, 1., 2011, Lisboa. Actas [...]. Lisboa: OBSERVARE, 2011. p. 01-18.

BRASIL. Lei 785 da República Federativa do Brasil, de 20 Ago 1949. Cria a Escola Superior de Guerra. [Brasília: Presidência da República, 1949].

BROCK, Lothar. Security through defending the environment: an illusion? In: Elise BOULDING (ed.), New Agendas for Peace Research: conflict and security reexamined, Boulder: Lynne Rienner, 1992. p. 79-102.

BULLA, Beatriz; LEOPOLDO, Ricardo; GIRARDI, Giovana; BERALDO, Paulo. Macron rebate Bolsonaro: não é questão de lobby, queremos ajudar futuro da Amazônia. O Estado de S. Paulo, São Paulo, 24 set. 2019. Disponível em: https://politica.estadao.com.br/noticias/geral/macron-rebate-bolsonaronao-e-questao-de-lobby-queremos-ajudar-futuro-da-amazonia,70003022952. Acesso em: 11 nov. 2019.

BURKE, Anthony et al. Planet politics: a manifesto from the end of IR. Millennium, London, v. 44, n. 3, p. 499-523, 2016.

BUZAN, Barry; HANSEN, Lene. The evolution of international security studies. Cambridge: Cambridge University Press, 2009.

BUZAN, Barry; WÆVVER, Ole. Regions and powers: the structure of international security. Cambridge: Cambridge University Press, 2003.

BUZAN, Barry; WÆVVER, Ole; WILDE, Jaap. Security: a new framework for analysis. Boulder: Lynne Rienner Publishers, 1998.

BUZAN, Barry. Peace, power, and security: contending concepts in the study of International Relations. Journal of Peace Research, Oslo, v. 21, n. 2, p. 109-125, 1984.

BUZAN, Barry. People, states and fear: an agenda for international security studies in post Cold War era. New York: Harvester and Wheatsheaf, 1991.

BYERS, Bruce. Ecoregions, state sovereignty and conflict. Bulleting of Peace Proposals, Oslo, v. 22, n.1, p. 65-76, 1991.

COLLINS, Alan. Contemporary security studies. 4. ed. Oxford: Oxford University Press, 2016.

CONCA, Ken. Rethinking the Ecology- Sovereignty Debate. Millennium, Journal of International Studies, London, v. 23, n.3, p. 701-711, 1994.

CRUTZEN, Paul. Geology of mankind. Nature, London, v. 415, n. 23, p. 23, 2002. DOI: 10.1038/415023a. Disponível em: htttps://doi.org/10.1038/415023a. Acesso em: 24 abr. 2021. 
CRUTZEN, Paul; STOERMER, Eugene. The Anthropocene. IGBP Global Change Newsletter, Stockholm, n. 41, p. 17-18, 2000.

DABELKO, Geoffrey; LONERGAN, Steve; MATTHEW, Richard. State-of-the-art review on environment, security and development co-operation. [S.l.]:

IUCN/OECD, 2002. Disponível em: http://www.iisd.

org/pdf/2002/envsec_oecd_review.pdf. Acesso em: 24 abr. 2021.

DALBY, Simon. Climate change. The RUSI Journal, London, v. 158, n. 3, p. 34-43, 2013.

DALBY, Simon. Rethinking security: ambiguities in policy and theory. Camberra: Peace Research Center, 1991.

DE FREITAS, Elizabete. Science studies and the metamorphic multiple Earth: Bruno Latour's risky diplomacy. Cultural Studies $\leftrightarrow$ Critical Methodologies, Champaign, v. 20, n. 3, p. 203-212, 2019.

DER DERIAN, James. A reinterpretation of realism: genealogy, semiology, dromology. In: DER DERIAN, James (ed.). International relations theory: critical investigations. Houndmills: MacMillan, 1995. p. 363-396.

DREIFUSS, René Armand. 1964: A conquista do Estado: ação política, poder e golpe de classe. Petrópolis; Rio de Janeiro: Vozes, 1981. 814p.

ECKERSLEY, Robin. Environmentalism and political theory: toward an ecocentric approach. Nova Iorque: State University of New York Press, 1992.

FARIA, Mariana, GIOVANELLA, Ligia; BERMUDEZ, Luana. A Unasul na assembleia mundial da saúde: posicionamentos comuns do conselho de saúde SulAmericano. Saúde em Debate [online], Rio de Janeiro, v. 39, n. 107, p. 920-934, 2015. DOI: 10.1590/0103-110420151070230. Disponível em:

http://www.scielo.br/scielo.php?script=sci_arttext\&pid=\$0103-

$11042015000400920 \& \operatorname{lng}=p t \& n r m=i s o$. Acesso

em: 24 abr. 2021. https://doi.org/10.1590/0103-110420151070230.

FARHI NETO, Leon. Concepções filosóficas ambientalistas: uma análise das diferentes perspectivas. ethic@-An international Journal for Moral Philosophy, Florianópolis, v. 5, n. 3, p. 33-56, 2006.

FORTI NETO, Octávio. Da UNASUL para o PROSUL: a visão do estado de direito e o regionalismo latino-americano. Conjuntura Global, Curitiba, v. 9, n. 1, p.130-149, 2020.

FERREIRA, Leila. A questão ambiental: sustentabilidade e políticas públicas no Brasil. São Paulo: Ed. Boitempo, 1998. 
FISCHER, Dietrich. Nonmilitary aspects of security: a systems approach: Aldershot. Dartmouth: UNIDIR, 1993.

FLEMES, Daniel et al. Una comunidad de seguridad regional en formación: la UNASUR y su Consejo de Defensa. Estudios Internacionales, Santiago del Chile, n. 170, p. 105-27, 2011.

FUCCILLE, Alexandre; REZENDE, Lucas Pereira. Complexo regional de segurança da América do Sul: uma nova perspectiva. Contexto Internacional, Rio de Janeiro, v. 35, n. 1, p. 77-104, 2013.

GARCIA, Francisco Proença. As ameaças trasnacionais e a segurança dos estados: subsídios para o seu estudo. Revista Negócios Estrangeiros, Lisboa: Ministério dos Negócios Estrangeiros - Instituto Diplomático, n. 9.1, p. 339-374, mar. 2006.

HAMMERSTAD, Anne. Whose security?: UNHCR, refugee protection and state security after the Cold War. Security Dialogue, Oslo, v. 31, n. 4, p. 391-403, 2000.

HOLLING, Crawford. Resilience and stability of ecological systems. Annual Review of Ecological Systems, Palo Alto, n. 4, p. 1-24, 1973.

HOUGH, Peter. Environmental security: an introduction. London: Routledge, 2014.

JONAS, Hans. El principio de responsabilidad: ensayo de una ética para la civilización tecnológica. Barcelona: Editoral Herder, 1995.

LEFF, Enrique. História ambiental. In: Saber Ambiental: sustentabilidade, racionalidade, complexidade, poder. Tradução de Lúcia Mathilde Endlich Orth. Petrópolis: Vozes, 2001. p. 385-402.

LEFF, Enrique. La complejidad ambiental. Ciudad del Mexico.: Siglo XXI Editores, 2000.

LIMA, Rosirene Martins; SHIRAISHI, Joaquim Neto. Conflitos socioambientais: o direito ambiental como legitimador da atuação do Estado no Jardim Icaraí, Curitiba. Ambient. soc., São Paulo, v. 18, n. 2, p. 129-144, jun. 2015.

LIPSCHULTZ, Ronnie. On security. New York: Columbia University Press, 1995.

LUZURIAGA, Fernández; GONZÁLEZ, H. Olmedo. Conflictividad y órdenes mundiales: la paz de Westfalia y la inauguración del sistema internacional contemporáneo. Critica Contemporánea. Revista de Teoría Política [en línea], Montevideo, n. 8, p. 48-75, 2018. Disponivel em: https://hdl.handle.net/20.500.12008/21106. Acesso em: 24 abr. 2021. 
MAOZ, Zee; RUSSETT, Bruce. Normative and structural causes of democratic peace, 1946-1986, American Political Science Review, Washington, v. 87, n. 3, p. 624-638, 1993.

MAOZ, Zeev. Domestic sources of global change. Ann Harbor: University of Michigan Press, 1996.

MARCHESAN, Ana Maria Moreira. O fato consumado em matéria ambiental. Salvador: JusPodvim, 2019.

MARTINELLI, Caio Barbosa. O jogo tridimensional: o hard power, o soft power e a interdependência complexa, segundo Joseph Nye. Conjuntura Global, Curitiba, v. 5, n. 1, p.65-80, 2016.

MATHIAS, Suzeley Kalil. A militarização da burocracia: a participação militar na administração federal das comunicaçőes e da educação, 1963-1990. Unesp, 2003.

MORIN, Edgar. A educação e a complexidade do ser e do saber. Rio de Janeiro: Vozes, 2010.

MOSLEY, Stephen. Common ground: integrating social and environmental history. Journal of Social History, Baltimore, v. 39, n. 3, p. 915-933, 2006.

NATO. Environment - NATO's stake. [S.l.], 2014. Disponível em: http://www.nato.int/cps/en/natohq/topics_91048.htm. Access on: 24 abr. 2021

NERY, Tiago. UNASUL: a dimensão política do novo regionalismo sul-americano. Cad. CRH, Salvador, v. 29, p. 59-75, 2016. Número Especial, 3.

NICOLESCU, Basarab et al. Educação e transdisciplinaridade I. Brasília: Unesco, 2000.

O'RIORDAN, Timothy; RAYNER, Steve. Risk management for global environmental change. Global Environmental Change, [s.l.], v.1, n. 2, p. 91-108, 1991.

OLDFIELD, Frank et al. The Anthropocene review: its significance, implications and the rationale for a new transdisciplinary journal. The Anthropocene Review, [s.l.], v. 1, n. 1, p. 3-7, 2013.

PRINS, Gwyn. Notes towards the definition of global security: global security programme. Occasional Paper 6. Cambridge: University of Cambridge, 1994.

RENNER, Michael. Assessing the military's war on the environment. In: State of the World. New York: L. Brown, 1991. p. 132-152. 
SANTOS NETO, Elydio. Por uma educação transpessoal: a ação pedagógica e o pensamento de Stanislav Grof. Rio de Janeiro: Lucerna, 2006.

SANTOS, Maria Helena de Castro. A nova missão das forças armadas LatinoAmericanas no mundo pós-Guerra Fria: o caso do Brasil. Rev. bras. Ci. Soc., São Paulo, v. 19, n. 54, p. 115-128, 2004.

SARAIVA, Miriam Gomes; SILVA, Álvaro Vicente Costa. Ideologia e pragmatismo na política externa de Jair Bolsonaro. Relações Internacionais, Lisboa, n. 64, p. 117-137, 2019.

SEMERARO, Giovanni. Intelectuais "orgânicos" em tempos de pósmodernidade. Cad. CEDES, Campinas, v. 26, n. 70, p. 373-391, Dic. 2006. Disponível em:

http://www.scielo.br/scielo.php?script=sci_arttext\&pid=S0101$32622006000300006 \& \operatorname{lng}=e n \& n r m=i s o$. Acesso

em: 25 abr. 2021. https://doi.org/10.1590/S0101-32622006000300006.

STEFFEN, Will et al. The trajectory of the anthropocene: the great acceleration. Anthropocene Review, [s.l.], v. 2 n.1, p. 81-98, 2015.

TANNO, Grace. A contribuição da escola de Copenhague aos estudos de segurança internacional. Contexto int., Rio de Janeiro, v. 25, n. 1, p. 47-80, 2003.

TAVOLARO, Sérgio Barreira de Faria. Movimento ambientalista e modernidade: sociabilidade, risco e moral. São Paulo: Annablume: FAPESP, 2001.

THIRY-CHERQUES, Hermano Roberto. Pierre Bourdieu: a teoria na prática. Rev. Adm. Pública, Rio de Janeiro, v. 40, n. 1, p. 27-53, 2006.

THOMAS, Caroline. The Third World security. In: CAREY, Roger; SALMON, Trevor C. (eds). International security in the modern world. New York: St. Martin's Press, 1992.

UGARTE, José Manuel. Los conceptos de defensa y seguridad en América Latina: sus peculiaridades respecto de los vigentes en otras regiones, y las consecuencias políticas de tales peculiaridades. Washigton: Lasa, 2001.

UNITED NATIONS HIGH-LEVEL PANEL ON THREATS, CHALLENGES AND CHANGE. A more secure world: our shared responsibility, New York: United Nations. Terrorism [s.l.], v.145, n. 164, p. 41, 2004.

UNITED NATIONS SECURITY COUNCIL. Press release: Security Council holds first-ever debate on impact of climate change on peace, security, hearing over 50 speakers, 2007. [s.l.], 2007. Disponível em:

http://www.un.org/press/en/2007/sc9000.doc.htm. Acesso em: 24 abr. 2021 
VAYRYNEN, Raimo. Concepts of security revisited (Book Review). Mershon International Studies Review, Oxford, v. 39, p. 259-262, 1995. Supplement, 2.

VILLA, Rafael Duarte. A segurança global multidimensional. Lua Nova: Revista de Cultura e Política, São Paulo, n. 46, p. 99-118, 1999.

VILLANUEVA Ayón, Miriam. La seguridad humana: ¿una ampliación del concepto de seguridad global?, Argentina Global, Buenos Aires, n. 3, p.106-130, 2000.

VIÑUALES, Jorge E. Law and the Anthropocene. C-EENRG Working Paper, Rochester, v. 4, 2016. Disponivel em: https://ssrn.com/abstract=2842546. Acesso em: 24 abr.2021

WAEVER, Ole et al. Identity, migration and the new security agenda in Europe. London: Pinter, 1993.

WATERS, Collin et al. The Anthropocene is functionally and stratigraphically distinct from the Holocene. Science, Washington, v. 351, n. 6269, aad2622, 2016. DOI: 10.1126/science.aad2622.

WCED. Our common future: report by the world commission on environmental and development. New York: Oxford University Press, 1987.

WESTING, Arthur. The environmental component of comprehensive security. Bulletin of Peace Proposals, Oslo, v. 20, n. 2, p. 129-134, 1989.

WICKSON, Fern et al. Transdisciplinary research: characteristics, quandaries and quality. Futures, [s.l.], v. 38, n. 9, p.1046-1059, 2006.

ZALASIEWICZ, Jan et al. Scale and diversity of the physical technosphere: a geological perspective. The Anthropocene Review, [s.l.], p. 1-14, 2016. 